\title{
A Prospective Study to Measure Drug Compliance in Epilepsy Patients
}

\author{
Padala Kalyani", Merugu Shravan Goud \\ Pharm. D Intern, Department of Pharmacy Practice, Bhaskar Pharmacy College, Yenkapally, Moinabad, Telangana, INDIA.
}

\begin{abstract}
Background: Epilepsy may promote limitations and restrain activities, interfering with the occupational ability, professional goals and social integration of patients. It increases morbidity and symptomatic epilepsy reduces life expectancy by 18 years at maximum. It continues to be a highly stigmatized and disabling chronic condition requiring a lifelong process of adherence to the prescriber's instructions and drug regimens. But many people cannot follow the order and seizure can occur from anti-epileptic drug withdrawal. So, measuring and monitoring of drug compliance is essential. Method: Totally 75 epilepsy patients were assessed, among which 60 patients who met the inclusion criteria were recruited into the study and were interviewed by using a structured questionnaire. The survey approach was used in the study. The study period was 6 months. Results: Majority (63\%) of the sample were compliant to the medication. According to the study, $27 \%$ of the sample stated cost factor as the reason for non-compliance. Among 29 (48\%) patients who experienced side effects, majority (43\%) suffered from drowsiness. Among 21 patients who had history of non-compliance [P-value $0.95>0.05$ level of confidence], $90 \%$ were non-compliant in the present study. Patient counselling was done, and patients were reassessed. Conclusion: After reassessment, majority (92\%) denied stopping medication in case of 2-3 months continuous absence of seizure episodes. This approach helped in $29 \%$ increment in drug compliance status among noncompliant individuals.
\end{abstract}

Key words: Epilepsy, Structured questionnaire, Measure, Drug-compliance, Patient counselling.

\section{INTRODUCTION}

An epileptic seizure is a transient occurrence of signs and/or symptoms due to abnormal excessive or synchronous neuronal activity in the brain. ${ }^{1}$ Epilepsy is a neurological disorder with reported prevalence of 6-8/100,000 incidence of 30-50/100,000 per year and cumulative incidence of $3 \%$. Compliance with medication is a major problem because of the need for longterm therapy together with unwanted effects of many drugs. ${ }^{2}$ According to the University of Tennessee Medical Center, there are four common types include Tonicclonic seizures, Absence seizures, Simple partial seizures, Complex partial seizures. ${ }^{3}$ Compliance behavior depends on the specific clinical situation, nature of illness, and the treatment program. An increased complexity of treatment regimen, as well as increased number of required behavioral changes appears to be associated with non-compliance. ${ }^{4}$ Patients can accidentally fail to adhere through forgetfulness, misunderstanding, or uncertainty about clinician's recommendations, or intentionally due to their own expectations of treatment, side-effects, and lifestyle choice. ${ }^{5}$

The aim of drug is to control and totally prevent all seizure activity at an acceptable level of side effects. ${ }^{6}$ Antiepileptic drugs are selected first and foremost according to clinical efficacy, then tolerability, drug interaction profile, and ease of use. $^{7}$ Treatment with standard anticonvulsants is often complicated by side effects. Up to 61 percent of patients with seizures report having side effects with antiepileptic drugs. ${ }^{8}$

AEDs can be narrow or broad spectrum. The narrow spectrum AEDs mostly work
DOI: 10.5530/ijopp.10.3.42

Address for correspondence: Padala Kalyani, Pharm. D Intern Bhaskar Pharmacy College Yenkapally Village Moinabad 501504 Telangana, INDIA. Phone No: 9701760098 Email Id: Padalakalyani.01@ gmail.com

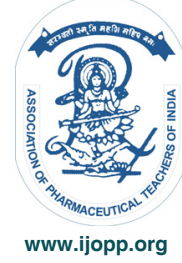


for specific types of seizures (such as partial, focal, or absence, myoclonic seizures). Broad spectrum AEDs additionally has some effectiveness for a wide variety of seizures (partial plus absence myoclonic seizures). ${ }^{9}$ Poor adherence to medication is major problem to sustained remission and functional restoration resulted in treatment failure and seizure recurrence. ${ }^{10}$

Medication adherence should be discussed regularly with the patient, and when a treatment seems to fail. There are several types of non-adherence. Therapeutic or medication non-adherence which includes failure to have the prescription dispensed or renewed, omission of doses, errors of dosage, incorrect administration, errors in the time and frequency of administration, and premature discontinuation of the drug regimen. A second type of non-adherence is dietary/exercise non-adherence in which the patient fails to follow the diet and exercise recommendations. A third type is the appointment nonadherence at which the patient fails to show up at clinics for the scheduled checkup. ${ }^{11}$ AEDs non-adherence will also lead to increase burden of inpatient and emergency department services; moreover, it also affects the family members socially, economically, and psychologically. ${ }^{12}$

\section{OBJECTIVES}

The main objectives of the study were to measure the drug compliance among epilepsy patients attending the Tertiary care hospital. The significance of the study is to find the major factors that are responsible for the noncompliance in the selected population there by counseling the patients and creating the awareness about the importance of the drug compliance and its positive effects on their quality of life, better seizure control and decreasing the hospitalization, morbidity and mortality.

\section{METHODS AND METHODOLOGY}

- Plan of work Study to measure drug compliance, preparation and submission of protocol, questionnaire, informed consent document to the hospital. Thereby obtaining Ethical Committee approval. The data was collected from the patients attending hospital; patients were interviewed by using a structured questionnaire. A survey method is used in this study. Drug compliance level was measured and there by identifying the factors affecting drug compliance. Awareness among patients is created by patient counseling. Reassessment about the drug compliance levels was done. The results were obtained by descriptive statistics.
- Study site the research study was conducted in Tertiary care hospital.

- Study design It is a prospective observational study and uses self-prepared questionnaire.

- Description of the tool Structured questionnaire or data collection form contains three parts, in which Part-I contains demographic details, Part-II contains disease data and Part-III contains medication data.

- Study period the study was conducted for six months.

- Inclusion criteria Patients with age above 12 years, Patients with epilepsy and other co-morbid diseases.

- Exclusion criteria Patients not providing ICD, Pediatric population was excluded, patients not willing to answer.

- Sources of data Case reports, laboratory data, interviewing patients, patients' care giver and physician.

- Sample people with epilepsy.

- Sample size 60 patients.

- Sampling technique purposive sampling.

- Pilot study A small study was conducted in advance of a planned project, specifically to test aspects of the study design and to allow necessary adjustment before final commitment to the design. ${ }^{13}$

- Plan of analysis A plan of analysis was developed after a pilot study. The data collected was coded, entered in the excel sheet and analyzed by descriptive statistics using chi-square test.

- Ethical committee approval Protocol of the study was submitted to hospital ethical committee. After the agreement by the hospital ethical committee members, it was approved by the ethical committee of Chakrapani Neuro Care Hospital, Nizamabad, Telangana.

\section{RESULTS}

Sample according to sex: Majority of patients suffering from seizure disorder are male patients. Among 60 $(100 \%)$ patients, there were $39(65 \%)$ male patients and $21(35 \%)$ female patients.

Indian Journal of Pharmacy Practice, Vol 10, Issue 3, Jul-Sep, 2017 
Marital status: Majority of patients suffering from seizure disorder are married. Among $60(100 \%)$ patients, $31(52 \%)$ patients are married and $29(48 \%)$ patients are unmarried.

Residence: Majority of patients belonged to rural area. Among 60 (100\%) patients, there were 58 (97\%) patients from rural area $2(3 \%)$ patients from urban area.

Educational status: Majority of sample had school education. Among 60 (100\%) patients, 28 (47\%) patients have school education, $20(33 \%)$ patients have no educational qualification, $4(7 \%)$ patients are graduates and $2(3 \%)$ patients are post graduates.

Employment status: Majority of the patients are employed. Among 60 (100\%) patients, 34 (57\%) patients are employed and $26(43 \%)$ patients are unemployed.

Type of family: Majority of the sample belongs to nuclear family. Among $60(100 \%)$ patients, 52 (87\%) patients belong to nuclear family and $8(13 \%)$ patients belong to joint family.

Family history of epilepsy: Majority of sample does not have family history of epilepsy. Among 60 (100\%) patients, $46(77 \%)$ patients do not have family history of epilepsy and $14(23 \%)$ patients have family history of epilepsy.

Age of onset of epilepsy: Majority of patient's age of onset of epilepsy was above 18 years. Among 60 (100\%) patients, $23(39 \%)$ patients' age of onset of epilepsy was in between 5 to 18 years and only $8(13 \%)$ patients' age of onset of epilepsy was below 5 years.

Years of illness: Majority of the patients have been suffering from epilepsy from past 1 year to 10 years. Among $60(100 \%)$ patients, $32(53 \%)$ patients have been suffering from epilepsy from past 1 year to 10 years, 15 $(25 \%)$ patients have been suffering from epilepsy since a few months, which is less than a year.

Type of therapy: Majority of the sample follows polytherapy. Among 60 (100\%) patients, 41 (68\%) patients are following polytherapy and $19(32 \%)$ patients are following monotherapy. The most commonly prescribed combination is Phenytoin and Valproic acid.

Frequency of medication: Majority of the patients were administering AEDs two times a day. Among 60 (100\%) patients, $52(87 \%)$ patients were receiving AEDs twice a day, $6(10 \%)$ patients were receiving AEDs thrice a day and only $2(3 \%)$ patients were receiving AEDs once a day.
Reason for drug noncompliance: Out of 22 $(100 \%)$ patients who were non-compliant, majority stated uncategorized reasons i.e., 9 (41\%) patients had uncategorized reasons, $6(27 \%)$ patients stated cost factor as the reason for noncompliance, $4(18 \%)$ patients often forget to take medication, $3(14 \%)$ patients stated that they did not benefit.

Previous history of noncompliance: Majority of the sample did not have previous history of noncompliance. Among $60(100 \%)$ patients, $39(65 \%)$ patients did not have any previous history of noncompliance, whereas $21(35 \%)$ patients have previous history of noncompliance.

Family members reminding to take medicine: Majority of the sample was not reminded to take their medication by family members. Among 60 (100\%) patients, $38(63 \%)$ patients do not need anybody's assistance and $22(37 \%)$ patients need to be reminded about the medication.

Development of side effects Majority of the sample did not experience any side effects i.e., among 60 (100\%) patients, $31(52 \%)$ patients did not experience any side effects whereas, $29(48 \%)$ patients experienced side effects.

Side effects effecting work: side effects were not problematic for majority of the patients. Among 60 $(100 \%)$ patients, $44(73 \%)$ patients are not affected by the side effects, whereas $16(27 \%)$ patients were affected by the side effects that are developed due to AED therapy.

Easy availability of medicine: Majority of patients had easy availability of medicines. Among $60(100 \%)$ patients, $58(97 \%)$ patients had easy availability of medicines and only $2(3 \%)$ patients had problem with availability of medicines.

Monthly Medicine Expenditures in Rupees: majority of the patients had monthly expenses up to Rs.1000/. Among $60(100 \%)$ patients, $42(70 \%)$ patients had monthly expenses of about Rs.1000/-, 16 (27\%) patients had monthly expenses in between Rs.1001/- to Rs.2000/and only $2(3 \%)$ patients had monthly expenses more than Rs.2000/-.

Follow up regularity: Majority of the patients who attended follow ups regularly. Among $60(100 \%)$ patients, $59(98 \%)$ patients attended regular follow ups and only 1 patient was irregular. 


\section{Table 1: Distribution of sample by diagnosis.}

\begin{tabular}{ccc} 
Diagnosis & Frequency & Percentage \\
\hline CPS & 22 & 36 \\
Febrile seizures & 1 & 2 \\
GTCS & 28 & 47 \\
Refractory seizures & 2 & 3 \\
Simple partial motor seizure & 1 & 2 \\
Status Epilepticus & 6 & 10 \\
Grand Total & 60 & 100 \\
\hline
\end{tabular}

- Among 60 patients, there were $28(47 \%)$ patients with GTCS, $22(36 \%)$ patients with CPS, $6(10 \%)$ patients with SE, $2(3 \%)$ patients with Refractory seizures, 1 $(2 \%)$ patient with Febrile seizures, and $1(2 \%)$ patient with Simple partial motor seizures.

\section{Table 2: Distribution of sample according to age.}

\begin{tabular}{ccc} 
Age Category & Frequency & Percentage \\
\hline $12-20$ & 22 & 37 \\
$21-40$ & 24 & 40 \\
$40-50$ & 8 & 13 \\
$>50$ & 6 & 10 \\
Total & & \\
\hline
\end{tabular}

- The age of the patients in the selected sample ranged from $12-62$. Mean is the average age of the patients suffering from seizure disorder is 29.2. Median is the central tendency of the age of the patients who are suffering from seizure disorder is around 25. Mode is the patients who are suffering from seizure disorder are mostly at the age of 15 .

\begin{tabular}{lcc}
$\begin{array}{l}\text { Table 3: Distribution of sample according to usage } \\
\text { of drugs. }\end{array}$ \\
\hline Name of AED & Frequency & Percentage \\
\hline Phenytoin & 30 & 32 \\
Valproic acid & 32 & 34 \\
Levetiracetam & 10 & 11 \\
Oxcarbamazepine & 10 & 11 \\
Clobazam & 7 & 7 \\
Carbamazepine & 4 & 4 \\
Phenobarbitone & 2 & 2 \\
Total & 95 & 100 \\
\hline
\end{tabular}

- Majority of the patients were using Valproic acid [34\%] and Phenytoin [32\%].

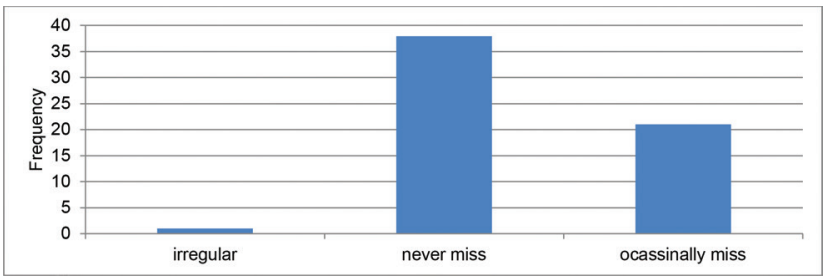

Figure 1: Distribution of sample according to compliance to AEDs.
- Majority of the sample are compliant to the medication. Among $60(100 \%)$ patients, 38 (63\%) patients never missed their dose and are compliant to the AEDs, 21 (35\%) patients occasionally missed their dose and $1(2 \%)$ patient was taking medicines irregularly.

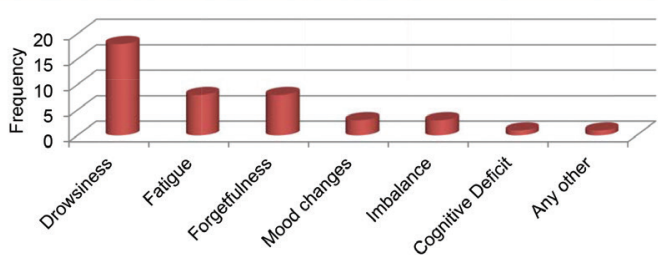

Figure 2: Distribution of Sample According to Type of Side Effects.

- Majority of sample experienced drowsiness [43\%], and then followed by fatigue [19\%], forgetfulness $[19 \%]$, mood changes [7\%], and imbalance [7\%].

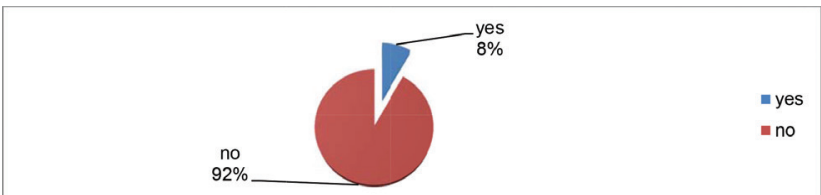

Figure 3: Distribution of Sample according to Patients Willing to Stop the medication if No Seizure Episode.

- Majority of patients denied stopping medication in case of 2-3 months continuous absence of seizure episodes. $5(8 \%)$ patients were willing to stop medication in case of 2-3 months continuous absence of seizure episodes.

- The objective of measuring the drug compliance in the epilepsy patients was attained and found to be $63 \%$.

\section{Factors influencing drug compliance}

Failure to comply with drug regimens is prevalent amongst patients with epilepsy and the consequence of this is often an increased risk of further seizures. ${ }^{14}$ Interpretation of data enables to check the dependency of each factor. The evaluation further gives information about the factors that contribute to the drug noncompliance.

\section{DISCUSSION}

For individuals with epilepsy, adherence to medication is crucial in preventing or minimizing seizures and their cumulative impact on everyday life. Non-adherence to antiepileptic drugs (AEDs) can result in breakthrough seizures many months or years after a previous episode and can have serious repercussions on an individual's perceived quality of life..$^{15}$

Indian Journal of Pharmacy Practice, Vol 10, Issue 3, Jul-Sep, 2017 


\section{Table 4: Factors influencing drug compliance}

\begin{tabular}{|c|c|c|c|c|c|c|}
\hline Variables & Category & $\begin{array}{l}\text { Compliant } \\
\text { frequency }\end{array}$ & $\begin{array}{l}\text { Non-complaint } \\
\text { frequency }\end{array}$ & Total & Chi square test & P-value \\
\hline \multirow{3}{*}{ Age } & $<29$ & 21 & 12 & 33 & 0.957 & 0.25 \\
\hline & $>29$ & 17 & 10 & 27 & & \\
\hline & & 38 & 22 & 60 & & \\
\hline \multirow{3}{*}{ Education } & School & 18 & 10 & 28 & 0.224 & 0.5 \\
\hline & >School & 20 & 12 & 32 & & \\
\hline & & 38 & 22 & 60 & & \\
\hline \multirow{3}{*}{ Place } & Urban & 1 & 1 & 2 & 0.274 & 0.5 \\
\hline & Rural & 37 & 21 & 58 & & \\
\hline & & 38 & 22 & 60 & & \\
\hline \multirow{3}{*}{ Duration of Illness } & $<10$ & 30 & 17 & 47 & 0.423 & 0.5 \\
\hline & $>10$ & 8 & 5 & 13 & & \\
\hline & & 38 & 22 & 60 & & \\
\hline \multirow{3}{*}{$\begin{array}{l}\text { History of non- } \\
\text { Compliance }\end{array}$} & Present & 13 & 8 & 21 & 0.000 & 0.95 \\
\hline & Absent & 25 & 14 & 39 & & \\
\hline & & 38 & 22 & 60 & & \\
\hline \multirow{3}{*}{ Side effects } & Present & 18 & 11 & 29 & 0.464 & 0.25 \\
\hline & Absent & 20 & 11 & 31 & & \\
\hline & & 38 & 22 & 60 & & \\
\hline \multirow{3}{*}{$\begin{array}{l}\text { Expenditure of } \\
\text { medicine }\end{array}$} & $<500$ & 12 & 7 & 19 & 0.257 & 0.5 \\
\hline & $>500$ & 26 & 15 & 41 & & \\
\hline & & 38 & 22 & 60 & & \\
\hline
\end{tabular}

\begin{tabular}{|c|c|c|c|c|c|c|}
\hline Variables & Category & $\begin{array}{l}\text { Compliant } \\
\text { frequency }\end{array}$ & $\begin{array}{l}\text { Non } \\
\text { Compliant } \\
\text { frequency }\end{array}$ & Total & chi square test & p-value \\
\hline \multirow[t]{3}{*}{ Sex } & Female & 12 & 9 & 21 & 0.465 & 0.25 \\
\hline & Male & 26 & 13 & 39 & & \\
\hline & & 38 & 22 & 60 & & \\
\hline \multirow[t]{3}{*}{ marital status } & Married & 19 & 12 & 31 & 0.734 & 0.25 \\
\hline & Unmarried & 19 & 10 & 29 & & \\
\hline & & 38 & 22 & 60 & & \\
\hline \multirow[t]{3}{*}{ employment status } & Employed & 19 & 15 & 34 & 0.171 & 0.5 \\
\hline & Unemployed & 19 & 7 & 26 & & \\
\hline & & 38 & 22 & 60 & & \\
\hline \multirow[t]{3}{*}{ type of family } & Joint & 4 & 4 & 8 & 0.401 & 0.5 \\
\hline & Nuclear & 34 & 18 & 52 & & \\
\hline & & 38 & 22 & 60 & & \\
\hline \multirow{3}{*}{ family h/o epilepsy } & No & 30 & 16 & 46 & 0.583 & 0.25 \\
\hline & Yes & 8 & 6 & 14 & & \\
\hline & & 38 & 22 & 60 & & \\
\hline
\end{tabular}




\begin{tabular}{|c|c|c|c|c|c|c|}
\hline \multirow{4}{*}{$\begin{array}{l}\text { age at which you } \\
\text { were diagnosed to } \\
\text { have epilepsy }\end{array}$} & $0-5 y r s$ & 6 & 2 & 8 & \multirow[t]{4}{*}{0.431} & \multirow[t]{4}{*}{0.5} \\
\hline & $5-18 y r s$ & 16 & 7 & 23 & & \\
\hline & \multirow[t]{2}{*}{$>18 y r s$} & 16 & 13 & 29 & & \\
\hline & & 38 & 22 & 60 & & \\
\hline \multirow[t]{4}{*}{ type of therapy } & Monotherapy & 15 & 4 & 19 & \multirow[t]{3}{*}{0.088} & \multirow[t]{3}{*}{0.75} \\
\hline & \multirow[t]{2}{*}{ Polytherapy } & 23 & 18 & 41 & & \\
\hline & & 38 & 22 & 60 & & \\
\hline & OD & 1 & 1 & 2 & \multirow[t]{4}{*}{0.702} & \multirow[t]{4}{*}{0.25} \\
\hline \multirow{3}{*}{$\begin{array}{l}\text { how frequently do } \\
\text { you take medicine }\end{array}$} & BID & 34 & 18 & 52 & & \\
\hline & TID & 3 & 3 & 6 & & \\
\hline & & 38 & 22 & 60 & & \\
\hline \multirow{3}{*}{$\begin{array}{l}\text { family member } \\
\text { reminding to take } \\
\text { medicine }\end{array}$} & No & 25 & 13 & 38 & \multirow[t]{3}{*}{0.604} & \multirow[t]{3}{*}{0.25} \\
\hline & Yes & 13 & 9 & 22 & & \\
\hline & & 38 & 22 & 60 & & \\
\hline \multirow[t]{3}{*}{$\begin{array}{l}\text { side effects } \\
\text { affecting work }\end{array}$} & No & 27 & 17 & 44 & \multirow[t]{3}{*}{0.600} & \multirow[t]{3}{*}{0.25} \\
\hline & Yes & 11 & 5 & 16 & & \\
\hline & & 38 & 22 & 60 & & \\
\hline
\end{tabular}

\section{Table 5: Percentage table of factors influencing drug compliance}

\begin{tabular}{|c|c|c|c|c|}
\hline Variables & Category & $\begin{array}{c}\text { Compliant } \\
\text { frequency (\%) }\end{array}$ & $\begin{array}{l}\text { Non-complaint } \\
\text { frequency (\%) }\end{array}$ & Total \\
\hline & $<29$ & 64 & 36 & 100 \\
\hline \multirow[t]{2}{*}{ Age } & $>29$ & 63 & 37 & 100 \\
\hline & School & 71 & 29 & 100 \\
\hline \multirow[t]{2}{*}{ Education } & >School & 56 & 44 & 100 \\
\hline & Urban & 100 & 0 & 100 \\
\hline \multirow[t]{2}{*}{ Place } & Rural & 62 & 38 & 100 \\
\hline & $<10$ & 66 & 34 & 100 \\
\hline \multirow[t]{2}{*}{ Duration of Illness } & $>10$ & 54 & 46 & 100 \\
\hline & Present & 10 & 90 & 100 \\
\hline \multirow[t]{2}{*}{ History of non-Compliance } & Absent & 92 & 8 & 100 \\
\hline & Present & 59 & 41 & 100 \\
\hline \multirow[t]{2}{*}{ Side effects } & Absent & 68 & 32 & 100 \\
\hline & $<500$ & 74 & 26 & 100 \\
\hline Expenditure of medicine & $>500$ & 59 & 41 & 100 \\
\hline
\end{tabular}

\begin{tabular}{ccccc} 
Variables & Category & $\begin{array}{c}\text { compliant } \\
\text { frequency } \%\end{array}$ & $\begin{array}{c}\text { non-compliant } \\
\text { frequency } \%\end{array}$ & total\% \\
\hline Sex & Female & 57 & 43 & 100 \\
& Male & 67 & 39 & 100 \\
Marital status & Married & 61 & 34 & 100 \\
& Unmarried & 66 & & 100
\end{tabular}




\begin{tabular}{|c|c|c|c|c|}
\hline & Employed & 56 & 44 & 100 \\
\hline Employment status & Unemployed & 73 & 27 & 100 \\
\hline \multirow{3}{*}{ Type of family } & Joint & 50 & 50 & 100 \\
\hline & Nuclear & 65 & 35 & 100 \\
\hline & No & 65 & 35 & 100 \\
\hline Family h/o epilepsy & Yes & 57 & 43 & 100 \\
\hline \multirow{4}{*}{$\begin{array}{l}\text { Age at which you were diagnosed } \\
\text { to have epilepsy }\end{array}$} & $0-5 y r s$ & 75 & 25 & 100 \\
\hline & $5-18 y r s$ & 70 & 30 & 100 \\
\hline & $>18 y r s$ & 55 & 45 & 100 \\
\hline & Monotherapy & 79 & 21 & 100 \\
\hline \multirow[t]{2}{*}{ Type of therapy } & Polytherapy & 56 & 44 & 100 \\
\hline & OD & 50 & 50 & 100 \\
\hline \multirow{2}{*}{$\begin{array}{l}\text { How frequently do you take } \\
\text { medicine }\end{array}$} & BID & 65 & 35 & 100 \\
\hline & TID & 50 & 50 & 100 \\
\hline \multirow{3}{*}{$\begin{array}{l}\text { Family member reminding to take } \\
\text { medicine }\end{array}$} & No & 66 & 34 & 100 \\
\hline & Yes & 59 & 41 & 100 \\
\hline & No & 61 & 39 & 100 \\
\hline Side effects affecting work & Yes & 69 & 31 & 100 \\
\hline
\end{tabular}

- History of noncompliance It is found that only $10 \%$ compliance rate is present among the patients who are non-compliant in the past and 92\% compliance rate is present among the patients who are not having history of non-compliance. This clearly states that history of non-compliance is the potential and major factor that is influencing the drug compliance. These results were similar with the study conducted by Vineetha J.R "A study to determine the drug compliance among people with epilepsy".

- Expenditure patients who had expenses less than Rs.500 shown to be more compliant (74\%) than the patients whose expenses are high. Majority of the patients stated cost factor as the reason for noncompliance. The major reasons for noncompliance stated by the patients were cost factor $(27 \%)$ and forgetfulness $(18 \%)$ which was supported by a study conducted by Asawavichienjida (2003) to measure compliance with treatment of adult epilepsy in Thailand, having majority reasons for noncompliance were forgetfulness $16.1 \%$ and economic problem. ${ }^{16}$
- Frequency of medication Patients taking medicines twice a day were found to be more compliant than the patients taking medicines thrice a day. The result was supported by a study conducted by Gomes and Filho (1998) to assess medication taking behavior and drug self-regulation of people with epilepsy. Patients took the drug more than once in most cases $(75.0 \%) .{ }^{17}$

- Our study says that $63 \%$ of patients never missed their dose, $48 \%$ of the patients had developed side effects which supported by a study by Buck and Jacoby (1997) to assess the factors influencing drug compliance with anti-epileptic therapy $(72 \%)$ of patient said they never missed taking their medication and $50 \%$ patients reported AEDs side effects. ${ }^{18}$

- Education The patients who are educated seem to be more compliant, which implies knowledge about the drug effects on the life style may help the patients to overcome non-compliant nature. The result was like a study conducted by Joanne Eatock "Managing patient adherence and quality of life". ${ }^{15}$ 
- Side effects patients suffering from side effects were $59 \%$ compliant whereas patients not suffering from side effects were $68 \%$ compliant. It shows that presence of side effects may influence the drug compliance in patients. The results were like the study of "Determinants of compliance in Saudi epileptic patients" by Mohammad Abdul Jabbar. ${ }^{19}$

- Duration of illness Patients suffering from epilepsy for the duration of less than 10 years were more compliant (66\%). But the compliance rate is shown to decrease among the patients who are suffering from more than 10 years (54\%). This implies lesser the duration of illness greater the compliance rates. These were supported by "Handbook of health behavior Research-II Provider Determinants" by David.S. Gochman. ${ }^{20}$

- Type of therapy patients following monotherapy found to be more compliant $(79 \%)$ than patients following polytherapy. These results were supported by Bruce Packham in the study of "How to improve compliance with AEDs". ${ }^{21}$

- The objectives of the study were achieved. The major factors influencing the drug compliance were found to be history of noncompliance, expenditure, frequency of medication, education, side effects, duration of illness, type of therapy. And depending on these factors the counseling was done. The patients were reassessed, and we found that majority of the patients who were non-compliant in the past denied stopping of medication. The compliance rate was increased by $29 \%$.

\section{Limitations}

The study was conducted for a short period of time. The patients were not admitted in the hospital and so, the communication was difficult in the outpatient department. Many patients were not willing to answer to the questionnaires and were included in exclusion criteria.

\section{Directions for the future study}

Clinical Pharmacists should create awareness about the risks associated with non-adherence and help the patients understand the importance of drug compliance in seizure control. Similar study can be done in pediatric patients. Similar plan of analysis can be used to check other factors influencing drug compliance.

\section{CONCLUSION}

Among $60(100 \%)$ patients, majority (47\%) of the patients were found to be diagnosed with GTCS and $36 \%$ of sample with CPS. Most of the epilepsy patients fall under the age group between 21-40yrs. Among 29 $(48 \%)$ patients who experienced side effects, majority $(43 \%)$ suffered from drowsiness. It is found that $63 \%$ of the sample found to be compliant. Drug compliance was found to be influenced significantly by the factors like education $(\mathrm{P}=0.5)$, duration of illness $(\mathrm{P}=0.5)$, side effects $(\mathrm{P}=0.25)$, expenditure $(\mathrm{P}=0.5)$, type of therapy $(\mathrm{P}=0.75)$, frequency of medication $(\mathrm{P}=0.25)$. Factor that is found to be influencing the drug compliance levels to the greater extent was history of non-compliance. Among 21 patients who had history of non-compliance [P-value $0.95>0.05$ level of confidence], $90 \%$ were non-compliant in the present study. Patient counseling was done according to the factors influencing drug compliance in each patient. Awareness was created among all the patients and reassessment was done. It is found that $92 \%$ of sample denied stopping medication which is $29 \%$ more compliant rate than the initial stage. The study was conducted to measure drug compliance and to identify the major factors which helped in counseling the patients appropriately and thus, helped in decrease of noncompliance nature in epilepsy patients.

\section{ACKNOWLEDGEMENT}

The authors extend their gratitude to Dr. A. Srinivasa rao, Principal of Bhaskar Pharmacy College, Hyderabad. The authors are also thankful to the institutional guide (K. Suvarna Laxmi) and the Hospital guide (Dr. B. Chakrapani) for their timely suggestions and guidance.

\section{CONFLICT OF INTEREST}

The authors declare no conflicts of interest

\section{ABBREVIATIONS}

P- value: Probability value; P: Probability value; AEDs: Antiepileptic drugs; ICD: Informed consent document; Rs.: Rupees; CPS: Complex partial seizures; GTCS: Generalized tonic clonic seizures; SE: Status epilepticus.

\section{SUMMARY}

This study was conducted with the objectives to determine 
the drug compliance in epilepsy patients and to find the major factors influencing the drug compliance. The study was conducted in a Tertiary care hospital with a sample size of 60 epilepsy patients. The patients were interviewed using a structured questionnaire. The factors influencing the drug compliance were found to be education, duration of illness, side effects, expenditure, type of therapy, frequency of medication and history of non-compliance. Patient counseling was done and awareness was created among every patient. On reassessment we found that, the study was helpful and the drug compliance rate was increased by $29 \%$ comparatively.

\section{REFERENCES}

1. Fisher RS et al, Epilepsia. 2005;46(4):470-2.

2. Kartik Shah et al, NHL Journal of Medical Science. 2015;4(1):75-82.

3. Resource Central, Neurology Now. 2008;4(6):36

4. Asadi-Pooya AA, Seizure. 2005;14(6):393-5

5. Eatock J, Baker GA. Neuropsychiatric disease and treatment. 2007;3(1):117-31.

6. Tripathi KD, Essentials of Medical Pharmacology. 2013;7:421.
7. Sander JW, Epilepsia. 2004;45(s6):28-34

8. Shah K, et al. NHL Journal of Medical Science. 2015;4(1):75-82.

9. Epilepsy Foundation, Summary of anti-epileptic drugs. 2014.

10. Getnet A, et al. Behavioral Neurology. 2016:1-6. Article ID-3189108.

11. Gabr WM, Mohamed E, Shams E, Saudi Pharmaceutical Journal. 2015;23(1):33-40.

12. Getnet A et al. Behavioral Neurology. 2016;1-6. Article ID-3189108.

13. https://www.aqr.org.uk/glossary/pilot-study

14. https://www.ncbi.nlm.nih.gov/pubmed/9153719

15. Eatock J, Baker GA, Neuropsychiatric disease and treatment. 2007;3(1):117-31

16. Asawavichienjinda $T$ et al, compliance with treatment of adult epileptics in a rural district of Thailand. Journal of medical association of Thailand. 2003;86(1):46-51

17. Gomes et al. Sci ELO Analytics, Arquivos de Neuro-psiquiatria. 1998:56(4).

18. Baker GA, Jacoby A, et al. Quality of life of people with epilepsy, A European study, Epilepsia. 1997;38(3):353-62

19. Abdul-Jabbar M. Determinants of compliance in Saudi epileptic patients, Annals of Saudi Medicine.1993;13(1):60-3.

20. David S. Gochman, Handbook of health behavior Research-II Provider Determinants. 2013;11: 219.

21. Bruce Packham, how to improve compliance with AEDs, February. 2009;20(3):12-20 